\title{
The philosophers' stone
}

\author{
Jonathan Simon ${ }^{1}$
}

Accepted: 7 June 2021 / Published online: 22 June 2021

(c) The Author(s), under exclusive licence to Springer Nature B.V. 2021

Many historians of science-and I would have to include myself among them-have only a superficial knowledge of alchemical texts and their associated traditions. A hermeneutic art par excellence, the history of alchemy has, until recently, been dominated by two opposing approaches, both heavily influenced by the rise of modern chemistry and the development of its own history. Starting already in the seventeenth and eighteenth centuries, so even before the chemical revolution and what has sometimes been labelled as the founding of modern chemistry, alchemy was increasingly viewed as non-scientific or even anti-scientific, a reputation reinforced by suspicions of atheism, associated with suspect practices bordering on natural (and maybe even supernatural) magic. Starting in the nineteenth, and well into the twentieth century the two opposing visions of alchemy portrayed it either as a purely symbolic representative practice, or as a secretive form of proto-chemistry, with its deliberately obscure writings based on sophisticated, empirical, chemical experimentation. Jung is, of course, the best-known representative of the first approach, while historians of chemistry like Berthelot or Partington promoted the second.

The ultimate quest—whether changing base metals into gold or the self-transformation of the adept in a parallel purification process - while condemned by modern chemists as illusory, still echoes in esoteric circles, particularly with respect to the quest for health (if not immortality), although once again, the elixir of life has been rejected as nonsense by modern secular medicine. Thus, in the second half of the twentieth century, while many found alchemy seductive as an area of research, it was hard to believe that it would manage to secure a respectable place in contemporary history of science. That was, of course, before the 'chymistry' movement at the end of the twentieth century. Launched by Larry Principe, this movement breathed new life into the history of alchemy, taking it seriously not only as chemistry, but also as a way of life for many alchemists; thereby, weaving the different strands together in a novel configuration.

Jennifer Rampling is part of a new wave of historians of alchemy, uncovering and exploiting manuscript sources that apparently have the potential to transform the field once again. A number of her hypotheses are debated in our review symposium

Jonathan Simon

jonathan.simon@univ-lorraine.fr

1 Archives Poincaré (UMR 7117), Université de Lorraine, Nancy, France 
of her book on the history of alchemy in England The Experimental Fire: Inventing English Alchemy 1300-1700. Together, these four articles make up an exchange between adepts of the history of alchemy that combines praise for Rampling's work on the English alchemical tradition with challenges to her arguments. Thus, we can enjoy exchanges around subtle points of exegesis and even subtler arguments about the reasons for attributing this or that manuscript to a particular figure from the history of alchemy at this particular date. The review symposium certainly gives a feeling for the commitment of these scholars to the field, as well as providing clues to where the history of alchemy might be heading with this new generation of scholars. This review symposium on alchemy is published alongside the usual mix of Metascience reviews on books in the history and philosophy of science, making for another stimulating issue. We hope that we are close to the magic formula that can transform this journal from paper into gold.

Publisher's Note Springer Nature remains neutral with regard to jurisdictional claims in published maps and institutional affiliations. 